\title{
A Experiência da Elaboração de um PCP: Um Caso de uma Indústria de Alimentos
}

\author{
An Experience of a PCP Elaboration: One Case of a Food Industry
}

Marcia Reis Mendes ${ }^{1}$

Luis Cordeiro de Barros Filho, M.Sc. ${ }^{1}$

${ }^{1}$ Escola Politécnica de Pernambuco, Universidade de Pernambuco, Recife, Brasil.

E-mail do autor principal: Marcia Reis Mendes macia.reis.mendes@hotmail.com

\section{Resumo}

Este artigo apresenta a experiência da implantação um Planejamento e Controle da Produção de uma Indústria Alimentícia. O artigo aborda uma visão macro do processo de Planejamento e realização do produto, desde a etapa de fechamento de capacidade fabril (levantamento de recursos), comparação do volume fabril com a demanda de vendas do comercial, planejamento e controle da programação de produção e da compra de insumos, até a disponibilização da programação de produção à área industrial, para elaboração do produto final. Tambémé referenciado ao longo do trabalho os requisitos do item 7.1. (Planejamento da realização do produto) da norma ISO 9001.

Palavras-Chave: Programação de Produção; Planejamento; Controle; Insumos; Plano de Produção; ISO 9001.

\begin{abstract}
This article consists of a deployment experience on Production Planning and Control of Food Industry. The article will show a macro view of the planning process and realization of the product, from the phase of manufacturing capacity definition (resource survey), comparison between the manufacturing volume and the sales demand, production planning and control and the purchase of inputs, as well as the availability of the production schedule to the industrial area for the manufacturing of the final product. It will also be referenced throughout the work the requirements of item 7.1. (Planning of product manufacturing) from rules ISO 9001.
\end{abstract}

Key-words: Production Scheduling; Planning; Control Resources; Production plan; ISSO 9001. 


\section{Introdução}

Com a grande exigência dos consumidores por produtos de qualidade, em tempo hábil e com variedade, além da crescente globalização e entradas de novos concorrentes no mercadoas empresas precisam sempre estar melhorando seus processos em busca de formas mais econômicas e eficazes para atenderem seus clientes.

Uma importante etapa na fabricação de um bem e ou prestação de serviço é o Planejamento e Controle da Produção (PCP), pois um bom planejamento de recursos e atividades irá influenciar diretamente na garantia da disponibilidade de produtos aos clientes bem como os aspectos econômicos para a empresa, uma vez que abrange a compra de insumos e a utilização dos recursos.

Para o autor [5] a capacidade de uma organização em competir no mercado é diretamente influenciada pelo posicionamento estratégico da organização, sendo necessário identificar os fatores críticos de sucesso (FSC). Os fatores críticos de sucesso por sua vez estão relacionados ao negócio da organização e ao seu desempenho em variáveis sobre as quais pode controlar. Ainda para o autor, vários dos fatores críticos de sucesso estão diretamente associados ao PCP.

Mesmo que os detalhese o grau de complexidade variem,toda e qualquer operação produtiva necessita de planos e controle. Algumas operações sendo mais difíceis de planejar do que outras, quando apresentam alto grau de imprevisibilidade. E outras com maior dificuldade em controlar, quando dispõem de um grande contato com o consumidor [8].

Diante da importância do setor de planejamento e controle da Produção paraqualquer tipo de organização produtiva, este trabalho relata a experiência da elaboração de um PCP em uma indústria alimentícia e tem por finalidade mostrar de forma macro como são feitas as etapas de planejamento e controle, além de referenciar alguns requisitos do item 7.1 (Planejamento da realização do Produto) da norma ISO 9001.

\section{Objetivos}

\subsection{Objetivos Gerais}

Mostrar a experiência da implementação, a importância e a relevância do Planejamento e Controle da produção para qualquer tipo de organização produtiva.

\subsection{Objetivos Específicos}

Expor uma experiênciados processos de planejamento e controle da produção em uma indústria alimentícia. Além de referenciar os requisitos do item 7.1 da norma ISO 9001.

\section{Fundamentação Teórica}

Para fundamentar o trabalho serão apresentados alguns conceitos sobre o Planejamento e Controle da Produção bem como o item 7.1 da norma ISO 9001.

\subsection{Introdução ao Planejamento da Produção}

A revolução Industrial proporcionou a criação e produção de meios para a produção de bens de consumo em massa. Os sistemas de Planejamento e Controle da produção (PCP) por sua vez evoluíram junto à evolução da ciência de administração. No início do século XX Taylor elaborou os princípios da administração Científica, os quais permitiram o desenvolvimento de muitos outros trabalhos.

Inicialmente os cálculos de Planejamento eram feitos de forma manual.Com o avanço tecnológico e com o aumento da complexidade de bens a serem produzidos, os cálculos tornaram-se inviáveis para serem executados manualmente, criando-se a necessidade de uso de outras ferramentas.

Em 1960 diversos pesquisadores compilaram vários métodos de cálculos no método chamado Materials Requirements plannning (MRP). Na década de 1970 com o surgimento dos computadores foram criados softwares MRPe este modelo passou a ser amplamente difundido, posteriormente evoluído para - Manufacturing Resources Planning (MRP II), em meados de 1980. Em 1990 com a crescente expansão do mercado as empresas iniciaram a popularização do sistema Enterprise Resources Planning (ERP), o qual permite o planejamento e controle não só dos recursos de produção, mas também de todos os outros recursos da empresa [5].

\subsection{Planejamento da Produção}

O Autor [7] define planejamento agregado como sendo um processo de balanceamento entre produção e demanda. O planejamento agregado procura nivelar a produção e demanda a um menor custo possível, sendo projetado para um horizonte em geral de 6 a 12 meses. O planejamento agregado fornece um 
quadro de referência para a busca de alocação de recursos, porém a implementação efetiva do mesmo exige que haja um desmembramento do planejamento em volume e prazo de cada produto que precisará ser produzido. A esta separação dá-se o nome de Plano de Produção ou Plano Mestre de Produção (PMP).

Ainda segundo o mesmo autor após a definição do plano mestre de produção inicia-se a etapa de programar e controlar a produção para obedecê-lo.

\subsection{Programação de Controle da Produção}

O Planejamento e Controle da Produção como uma função administrativa que tem por objetivo construir planos que direcionarão a produção bem como seu controle, ou seja, define: o que, quanto, como, onde, quem e quando será produzido [2].

A programação e o controle da produção são atividades que marcam o fim de um ciclo de planejamento mais longo, desde o planejamento de capacidade e o planejamento agregado, e inicia-se uma etapa operacional. Para as atividades industriais a operação de programação tem como primeiro passo a alocação de carga, que tem por objetivo distribuir as atividades de trabalho pelos centros operacionais. Em seguida temos o sequenciamento das tarefas que tem por finalidade a definição da ordem na qual as atividades serão processadas [7].

Ainda segundo [7] o controle da produção está associado ao cumprimento da programação de produção com relação a forma de produção, data e quantidade produzida.

Para [8] controlesão todos e quaisquer ajustes realizados que permitem que a operação atinja os objetivos estabelecidos pelo plano, monitorando o que realmente acontece e se preciso fazendo mudanças.

\subsection{Planejamento da Realização do Produto da Norma ISO 9001- Requisito 7.1}

O Planejamento é algo ativo que deve ser sempre repensado conforme mudanças de tecnologias, novos concorrentes, variação de demanda, sempre buscando a melhoria contínua de seus processos [3].
Planejamento da realização do produto os seguintes itens [1]:

- Os objetivos da qualidade; os requisitos para o produto: a especificação do produto;

- Estabelecer os processos, documentos e recursos necessários para a realização do produto. Sendo exemplo de recursos: mão-deobra, instalações, máquinas; insumos, softwares, etc;

- Requisitos para aceitação do produto, como: verificação, validação, monitoramento, medição, inspeção e atividades de ensaios requeridos, específicos para o produto;

- Registros que forneçam evidências de que o processo de realização do produto e o produto final atendem aos requisitos;

\section{Metodologia}

Os autores [4] classificam uma pesquisa como pura ou aplicada dependendo de sua finalidade. A pesquisa pura é caracterizada pela busca do progresso científico e a ampliação de conhecimentos teóricos, sem levar em consideração a utilização prática. Já a pesquisa aplicada tem por objetivo a utilização dos resultados para a solução de problemas reais, ou seja, apresenta fins práticos. Diante da definição acima, o artigo enquadra-se em uma pesquisa aplicada, já que trata-se da experiência da elaboração de um PCP em uma indústria alimentícia.

Um estudo de caso é caracterizado por um trabalho de caráter empírico cujo objetivo é investigar um fenômeno atual por meio da análise de um ou mais casos [6]. Diante desta definição o levantamento de dados tratou-se de um estudo de caso com o relato da experiência de um PCP já implantado e em funcionamento de uma indústria alimentícia.

\section{Estudo de Caso}

\subsection{Planejamento da Realização do Produto da Norma ISO 9001- Requisito 7.1}

A empresa estudada foi fundada na década de 1990 e está localizada na região Nordeste do Brasil. Atualmente a empresa integra o maior grupo Alimentício de Massas e Biscoitos do País. Hoje produz mais de 200 StockKeeping Unit(SKU) dentre Biscoitos 
e Massas. É composta por 5 unidades produtivas, distribuídas em duas áreas fabris.

\subsection{Planejamento da Realização do Produto da Norma ISO 9001- Requisito 7.1}

Este trabalho descreve a experiência de um Planejamento e Controle da Produção (PCP) em uma indústria alimentícia e fazer referência ao item $7.1 \mathrm{da}$ norma ISO 9001-Planejamento da Realização do produto.

A Figura 1, a seguir, mostra de forma macro as etapas que compõem o processo de Planejamento e Controle da Produção da indústria alimentícia que serão detalhados em sequência ao longo do Estudo de Caso.

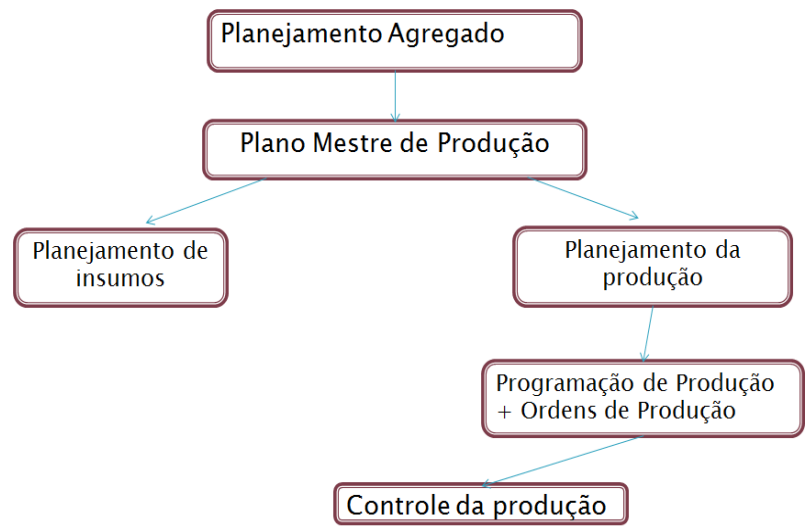

Figura 1: Etapas do Planejamento e Controle da Produção Fonte: A autora, 2016

\subsection{Planejamento Agregado (Demanda de Vendas $x$ Fechamento de Capacidade)}

Anualmente a organização defineum orçamento para o ano seguinte com base no crescimento que a organização busca alcançar no mercado de acordo com o Planejamento estratégico da empresa.Com base neste orçamento o setor de Planejamento e Controle da Produção estrutura os recursos junto à área industrial de forma a atender a demanda planejada pela empresa para o ano seguinte.

A empresa utiliza uma Planilha de Capacidade, que detém todas as informações de como está programada a fábrica, com relação a turnos de trabalho, as paradas programadas por feriados, manutenção e outros eventos programados que possam influenciar na capacidade produtiva.
A Planilha de Capacidade contém todo o volumeprevisto a ser realizado mês a mês bem como os volumes a serem produzidos por linha de produção a fim de atingir a meta traçada do ano.

Além do setor do Planejamento e Controle da Produção existe um setor denominado planejamento logístico responsável por mediar o planejamento agregado, ou seja, fazer um balanço entre a demanda prevista de vendas (enviada pelo setor comercial) e a capacidade de produção (enviada pelo setor do PCP)

Ao final de cada mês o PCP com base na Planilha de Capacidaderevisa as capacidades fabris para um horizonte de 3 meses de acordo com a perspectiva de demanda passada pelo Planejamento Logístico. Caso haja um aumento forte na demanda que exceda o planejamento inicial o PCP deve avaliar junto à área industrial a possibilidade de diminuir alguma parada programada, aumentar turnos de produção ou até mesmo rodar em feriados considerando pagamento de Horas extra. Ssempre levando em conta os tratamentos ambientais programados, de forma a não comprometer a qualidade e segurança dos alimentos fabricados.

Se mesmo após a negociação do PCP com a indústria para aumento de capacidade, a demanda de vendas estiver muito além da capacidade produtiva, o Planejamento Logístico deve informar ao Comercial a limitação de capacidade para que o mesmo redefina o Plano de vendas do mês. A fim de ter maior lucratividade para a empresa, ou seja, definir quais produtosserão necessários reduzir do volume inicial para ser considerado no plano de produção do mês.

Caso a demanda de vendas esteja inferior ao planejamento inicial, havendo sobra de capacidade para o mês que se iniciará e/ou os próximos meses, o PCP deve, em conjunto com a indústria, encontrar soluções que possam diminuir a capacidade ofertada sem incorrer em custos à empresa e à qualidade dos produtos. Como por exemplo: antecipar férias dos colaboradores, utilizar o tempo de linha parada para capacitar os colaboradores, antecipar manutenções ou demais serviços que necessitem dalinha de produção parada para ser executado.

Ao final de cada mês tanto o setor do PCP quanto o Comercial devem rever seus planos de capacidades e de vendas para inclusão do terceiro mês (não contemplado na previsão anterior), além de revisar os dois outros meses já previstos inicialmente, caso haja alguma alteração de recurso que vá alterar a capacidade prevista ou até mesmo alguma variação de mercado que possa influenciar significativamente nas vendas. Em seguida, com as capacidades e a demanda de vendas definidas repete-se o processo de validação das mesmas. 
Nesta etapa do Planejamento a empresa considera uma metodologia Just in Case- JIC, uma vez que toda a execução do planejamentoé feita em cima de uma previsão de vendas passada pelo comercial.

\subsubsection{Definição do Plano Mestre de Produção}

Após a capacidade de produção e a demanda de vendas definidas (planejamento agregado), o planejamento é destrinchado por tipo de produto e volume passando a compor o chamado Plano Mestre de Produção ou plano de Produção. Este Plano de Produção é o compromisso assumido pela indústria para produção e pelo comercial paraas vendasdo mês que se inicia e uma previsão para os dois meses subsequentes. Na Tabela 1, a seguir, é mostrado o Plano Mestre de Produção:

Tabela 1: Plano Mestre de Produção para três meses Fonte: A autora, 2016

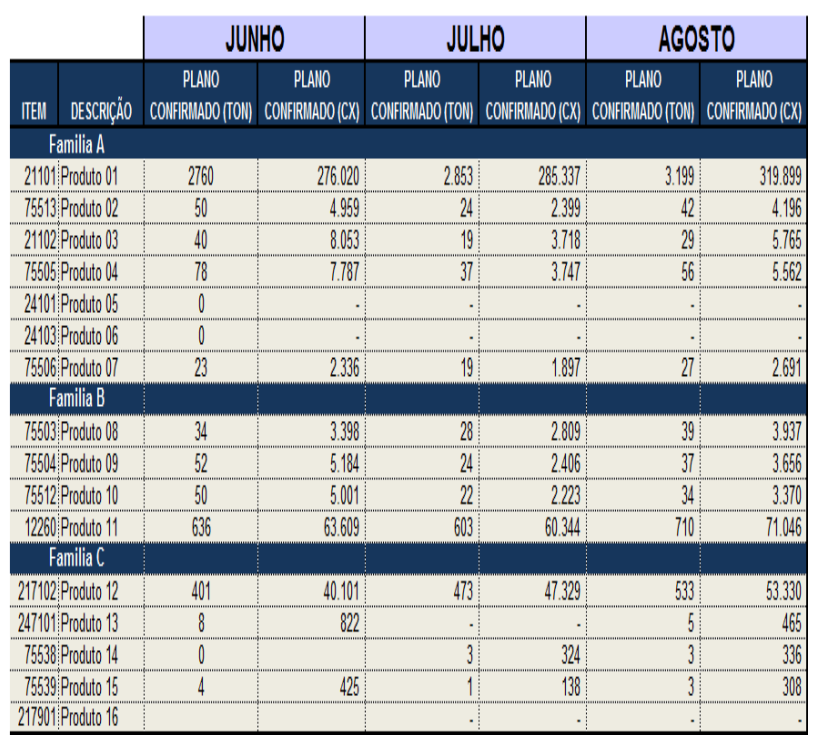

Com o Plano Mestre de Produção definido oPlanejamento logístico deve ao primeiro dia do mês inserir no ERP da empresa as informações para que o sistema gere oMRP. O sistema ERP possui cadastradas todas as informações do requisitodo produto, bem como todos os itens que vão compor o produto final, desta forma o sistema gera as quantidades de materiais necessárias, bem como o prazo de chagada dos insumos de forma a garantir o cumprimento do Plano mestre de produção para os três meses em questão. As informações contidas no ERP remetem ao item "a" do requisito 7.1 da ISO 9001.

\subsection{Planejamento Agregado (Demanda de Vendas $x$ Fechamento de Capacidade)}

Com base nas informações geradas pelo MRP o PCP deve fazer a gestão dos insumos e da programação de produção para a execução do Plano mestre de Produção do mês em questão e o planejamento dos dois meses seguintes.

\subsubsection{Planejamento de Insumos}

O planejamento dos insumos é dividido em três partes para facilitar a gestão: matéria-prima , embalagem e caixas.

O Planejador de insumosdeve avaliaros volumese prazos de entrega gerados pelo MRP,os estoques já existentes do item na unidade produtora, bem como os pedidos em aberto. Após análise concluída, 0 planejador de insumos deve colocar no sistema ERP a requisição(s) de compra para o setor de suprimentos, informando o insumo a ser comprado, a quantidade e a confirmação doprazo de recebimento necessários. Suprimentos, por sua vez, deve efetivar a requisição de compra junto ao fornecedor, transformando-a em pedido de compra. As requisições de compra devem ser colocadas no sistema para os dois meses seguintes, uma vez que os insumos do mês corrente já devem estar nos estoques ou em rota de entrega para garantir o atendimento do Plano Mestre de Produção do mês.

Após a colocação do pedido para o fornecedor, - PCP deve fazer o follow-up de entrega junto ao mesmo, a fim de garantir a disponibilidade do insumo para a produção no tempo correto e na quantidade necessária e, em consequência, cumprimento do Plano Mestre de Produção.

As requisições devem ser colocadas pelo PCP respeitando o lead time de entrega do fornecedor previamente acordado na homologação do mesmo à empresa. Apesar da divisão dos insumos a rotina de planejamento segue o mesmo raciocínio para os três tipos, divergindo apenas em alguns detalhes de acordo com a particularidade do insumo a exemplo de prazo de validade para estocagem.

http://dx.doi.org/10.25286/repa.v2i2.543 


\subsubsection{Planejamento de Produção}

O Programador de produção tem por objetivo programar a produção da fábrica e disponibilizá-la à indústria para que seja executada.

A programação de produção é feita com base no Plano de Produção do mês, nos estoques de produto acabado existente na fábrica junto a colocação de pedidos pelos clientes para cada Stock Keeping Unit (SKU- Unidade de Manutenção de Estoque- Definição de diferentes tipos de materiais/produtos no estoque) . Com base nas informações citadas, o programador monta uma programação semanal na qual possui todas as linhas de produção bem como o SKU que deverá ser produzido em cada linha e a quantidade, informando tempos de setups (inicialização da produção de um novo produto), manutenções preventivas, e outras paradas que estejam programadas.

O sequenciamento dos produtos é feito de forma a cumprir o plano de produçãoe garantir a disponibilidade do máximo de produtos em estoque, priorizando a produção dos que estiverem sem estoque, principalmente sem estoques e já com pedidos colocado ou com estoques mais baixos, ou seja,nesta etapa a empresa utiliza-se da metodologia Just in time-JIT dado que a produção é direcionada prioritariamente para atendimento dos pedidos em carteira.

Abaixo nas Tabelas 2 e 3 temos um exemplo do acompanhamento do Plano de produção ao longo do mês e dos estoques de produtos que são utilizados como base para programação.

Tabela 2: Acompanhamento Plano de Produção (em ton) Fonte: A autora, 2016
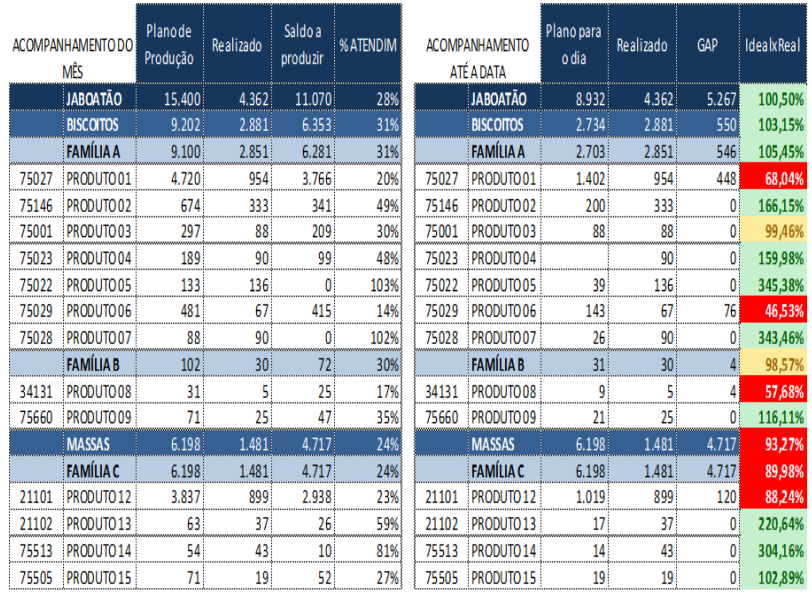

A programação de produção é revisada diariamente considerando também a disponibilidade dos insumos necessários para a produção do SKU a ser programado. Caso não se tenha o insumo em estoque no momento da revisão da programação, o SKU não deverá ser programado, a fim de evitar transtornos de iniciar a produção e a mesma ser interrompida por falta de insumo. Se o insumo estiver limitado ao volume programado o PCP deverá informar esta limitação na planilha de programação. O PCP só poderá considerar os estoques dos insumos já inspecionados e liberados pela qualidade, os quais tem seus saldos disponíveis no sistema ERP.

Tabela 3: Acompanhamento Plano de Produção (em ton) Fonte: A autora, 2016

\begin{tabular}{|c|c|c|c|c|}
\hline CÓDIGO & PRODUTO & $\begin{array}{l}\text { ESTOQUE } \\
\text { CAIXAS }\end{array}$ & $\begin{array}{c}\text { ESTOQUE } \\
\text { TON }\end{array}$ & $\begin{array}{c}\text { DIAS } \\
\text { ESTOQUE }\end{array}$ \\
\hline 48019 & PRODUTO 01 & 8.042 & 64 & 3 \\
\hline 48018 & PRODUTO 02 & 1.223 & 10 & 39 \\
\hline 48012 & PRODUTO 03 & 5.358 & 45 & 33 \\
\hline 48219 & PRODUTO 04 & 35 & 0 & \\
\hline 48215 & PRODUTO 05 & 87 & 1 & 66 \\
\hline 48213 & PRODUTO 06 & 109 & 1 & 152 \\
\hline 32111 & PRODUTO 07 & 57 & 0 & 3 \\
\hline 32118 & PRODUTO 08 & 5 & 0 & 0 \\
\hline 32119 & PRODUTO 09 & 3.703 & 30 & 1 \\
\hline 32105 & PRODUTO 10 & 0 & 0 & 0 \\
\hline 32114 & PRODUTO 11 & 53 & 0 & 18 \\
\hline 32110 & PRODUTO 12 & 143 & 1 & 22 \\
\hline 30118 & PRODUTO 13 & 1 & $\overline{0}$ & \\
\hline 11033 & PRODUTO 14 & 3 & 0 & \\
\hline 30105 & PRODUTO 15 & 90 & 1 & 65 \\
\hline 11012 & PRODUTO 16 & 0 & 0 & \\
\hline 30103 & PRODUTO 17 & 0 & 0 & \\
\hline 75000 & \begin{tabular}{|l|} 
PRODUTO 18 \\
\end{tabular} & 3.049 & 24 & 25 \\
\hline 75032 & PRODUTO 19 & 9.539 & 76 & 4 \\
\hline 75524 & PRODUTO 20 & 0 & 0 & \\
\hline 75529 & PRODUTO 21 & 6.040 & 51 & 15 \\
\hline 75033 & PRODUTO 22 & 14.204 & 114 & 4 \\
\hline 75146 & PRODUTO 23 & 17.077 & 143 & 5 \\
\hline 75022 & PRODUTO 24 & 5.240 & 44 & 8 \\
\hline 75023 & PRODUTO 25 & 10.611 & 85 & 22 \\
\hline 75028 & PRODUTO 26 & 10.514 & 84 & 44 \\
\hline 75029 & PRODUTO 27 & 7.575 & 61 & 11 \\
\hline 75001 & PRODUTO 28 & 10.934 & 87 & 20 \\
\hline
\end{tabular}

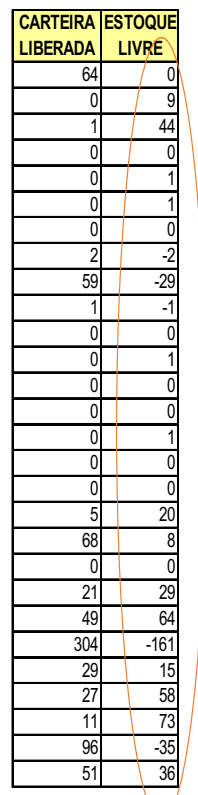

Na Tabela 4 segue exemplo de planilha utilizada pelo PCP para sequenciamento da produção e divulgação da programação para a indústria.

Tabela 3: Acompanhamento Plano de Produção (em ton) Fonte: A autora, 2016

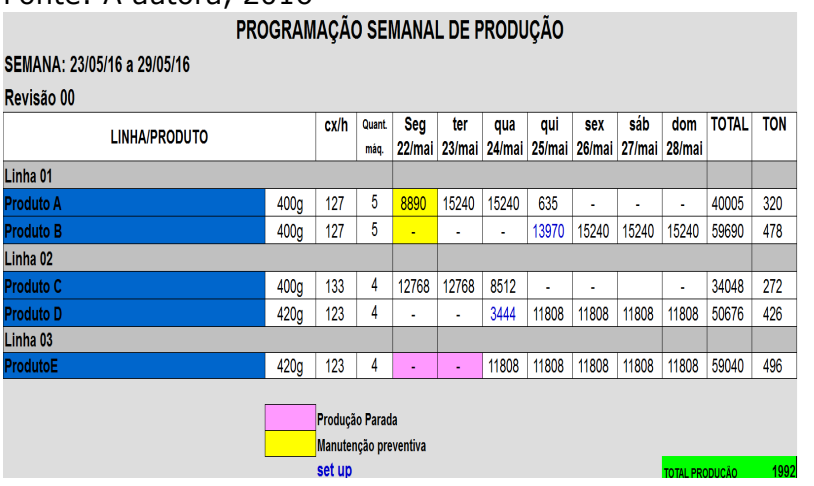

Com base na programação semanal o PCP cria no ERP as Ordens de Produção (OPs) que serão destinadas à indústria para o lançamento da produção realizada.Cada SKU a ser produzido deve ter uma ordem de produção correspondente, informando a 
quantidade a ser produzida, bem como a linha e o período de produção (início/fim). Um relatório com o número das ordens de produção é enviado à área industrial,no dia anterior à produção, via e-mail para, que com base na OP cadastrada, a produção consiga informar no sistema ERP o volume produzido. Apenas nas sextas-feiras são criadas e enviadas as Ordens de Produçãoreferentes ao final de semana e da segundafeira da semana seguinte.

A programação semanal, Figura 4, também é disponibilizada à produção via e-mail para a área industrial a fim de ter-se uma visão macro do planejamento da semana. As sextas-feiras é enviada à programação semanal da semana seguinte, que por sua vez será revisada diariamente ao longo da semana. A cada revisão de programação é informada a mudança as áreas envolvidas bem comoregistrado na planilha o número da revisão. O uso de uma planilha padrão de programação, atualização da revisão feita bem como os processos de divulgação da programação da produção para a área industrial remete a prática do item " $b$ " (necessidade de estabelecer processos e documentos e prover recursos específicos para o produto) do requisito 7.1 da ISO 9001.

\subsection{Controle da Produção}

O acompanhamento do cumprimento das OPs permite que ao PCP possa ter o controle da produção, ou seja, se o realizado está de acordo com o que foi programado. Este controle é feito diariamente referente as OPs do dia anterior. O não atendimento das OPs é monitorado para justificar e encontrar a causa do descumprimento da ordem programada. A indústria deve tratar o motivo do não cumprimento da programação para evitar a recorrência do erro e consequentemente o não cumprimento do Plano de Produção.

Ao fim da produção, após o produto acabado devidamente apontado no sistema, a qualidade inspeciona o produto para fazer a sua liberação para estoque e posteriormente para o centro de distribuição. Caso o produto seja reprovado por alguma não conformidade a qualidade informa no sistema a retenção do produto defeituoso para que o saldo produzido não seja contado como produto liberado para o PCP. Esta forma garante que o PCP reprograme o produto defeituoso e que o produto final não siga, não conforme, para a distribuição.

Além do controle do volume produzido, o PCP deve ter o controle dos insumos a serem utilizados na produção. No processo de recebimento do insumo a 13 qualidade deve analisar o material recebido conforme especificação padrão a fim de liberar ou não seu uso. Em caso de não conformidade, no material recebido o PCP deve ser comunicado e o saldo do insumo deve ser segredado do estoque físico e no sistema ERP. A Qualidade informará ao setor de suprimentos o motivo da não conformidade para que o mesmo solicite ao fornecedor uma tratativa da não conformidade a fim de que o problema não torne a se repetir. O PCP por sua vez, com o saldo atualizado no sistema deverá reprogramar uma nova compra do insumo tido como defeituoso para repor o estoque do item.

Nesta etapa percebe-se de forma clara os requisitos " $c$ " e " $d$ " do item 7.1 da norma ISO 9001 sendo postos em prática no processo de controle da produção. Dado que a qualidade realiza um processo de aprovação/rejeição tanto do produto acabado quanto do insumo a ser utilizado bem como as OPs servem como um registro da produção já analisada que está em conformidade com os limites especificados.

\section{Conclusões}

O artigo mostrou a experiência dos processos de planejamento, execução e controle um PCP de uma indústria de alimentos, de forma macro, e expôs a importância do planejamento e controle da produção para o negócio de qualquer empresa. Um planejamento bem executado permite que a organização utilize damelhor maneira os seus recursos, evitando desperdícios e gastos desnecessários. O controle da produção permite que a empresa corrija seus processos, quando necessário, e verifique o cumprimento da programação estabelecida, bem como a verificação dos recursos utilizados. Desta forma, a empresa torna-se mais competitiva, uma vez que otimiza seus recursos e processos de forma a atender a necessidade de mercado em tempo hábil e com variedade solicitada. O modelo apresentado fornece também uma opção para a área de planejamento da realização do produto para empresas que buscam a certificação da ISO 9001.

\section{Referências}

[1] ASSOCIAÇÃO BRASILEIRA DE NORMAS TÉCNICAS. NBR ISO 9001: Sistemas de

http://dx.doi.org/10.25286/repa.v2i2.543 
gestão da qualidade-requisitos. Rio de Janeiro, 2008.

[2] FUSCO.J.P.A; SACOMANO.J.B.Operações e Gestão estratégica da produção.Arte e Ciência. São Paulo, 2007.

[3] FREITAS, A. ISO 9001:2008-7.1 Planejamento da Realização do Produto. http://academiaplatonica.com.br/2011/gestao/is o-90012008-7-1-planejamento-da-realizacao-doproduto/. Acesso em: 14 de Junho de 2016.

[4] LAKATOS, E.M.; MARCONI, M.A. Técnicas de Pesquisa: Planejamento e execução de pesquisas. Amostragens e técnicas de pesquisa. Elaboração, análise e interpretação de dados. Atlas S.A. São Paulo, 2008.

[5] LUSTOSA, L; MESQUITA, M. A.; QUELHAS, O; OLIVEIRA, R. Planejamento e Controle da Produção. Elsevier, Rio de Janeiro, 2008.

[6] MIGUEL, P.C \& SOUSA, R. Metodologia de Pesquisa em: Engenharia de Produção e Gestão de Operações. Elsevier. Rio de Janeiro, 2012.

[7] MOREIRA.A.D. Administração da Produção e Operações. Cengage Learning. São Paulo, 2008.

[8] SLACK, N; CHAMBERS, S; JOHNSTON, R. Administração da Produção. Atlas S.A. São Paulo, 2009. 